\title{
Intraductal Papillary Mucinous Neoplasia of the Pancreas - Pathologic Features and Molecular Markers - A Review
}

\author{
Rui Caetano Oliveira ${ }^{1,2}$, Maria Augusta Cipriano ${ }^{1}$
}

'Pathology Department, Centro Hospitalar e Universitario de Coimbra, 3000-075, Coimbra, Portugal ${ }^{2}$ Coimbra Institute for Clinical and Biomedical Research (iCBR) area of Environment Genetics and Oncobiology (CIMAGO), Faculty of Medicine, University of Coimbra, 3000-548 Coimbra, Portugal
Corresponding author:

Rui Caetano Oliveira, MD

Pathology Department, Centro Hospitalar

e Universitario de Coimbra, 3000-075

Coimbra, Portugal

E-mail: ruipedrocoliveira@hotmail.com

\section{ABSTRACT}

Intraductal papillary mucinous neoplasm (IPMN) of the pancreas are pre neoplastic lesions defined by the World Health Organization as a grossly visible intraductal epithelial neoplasm that arises in the pancreatic ductal system, composed of mucin producing cells. The predisposing factor for their development as well as genetics are still largely unknown. Pathologists have a pivotal role in IPMN management since features like IPMN subtype, degree of atypia, margins status and presence or absence of an invasive component imply different patient management. In this article, we perform a review of the pathological features and molecular markers of IPMNs.

Key words: pancreas, intraductal papillary mucinous neoplasm, pathology, molecular markers

\section{INTRODUCTION}

The intraductal papillary mucinous neoplasm (IPMN) of the pancreas was first described in 1982 (1) and is defined by the World Health Organization (WHO) as a grossly visible intraductal epithelial neoplasm that arises in the pancreatic ductal system, composed of mucin-producing cells. IPMNs are rather common lesions, more prevalent in the older population $(2,3)$. Some authors have described gender - and regional-specific differences, with IPMNs being more common in males in Eastern countries, while in Western countries there may be no difference in IPMN propensity between genders (4).

Currently, there are no well-established risk factors for IPMN development (2) but some have been linked it to genetic syndromes like familial adenomatous polyposis, Peutz-Jeghers and even Lynch syndrome $(5,6)$.

The pathogenesis is not fully understood, but IPMNs often show progression to invasive adenocarcinoma via the adenoma-carcinoma sequence. Knowledge of the biological behavior is fundamental for a precise diagnosis and appropriate patient management (7).

Pathology evaluation is crucial for the correct characterization of the IPMNs in order to establish markers for patient risk stratification, both in pre and postoperatory context. 


\section{Importance of pathological evaluation}

Pancreatic cysts encompass a wide variety of neoplastic and non-neoplastic entities, the most prevalent being IPMNs, mucinous cystic neoplasm (MCN), and serous cystadenomas (8). The management of patients with pancreatic cysts is highly dependent on the subtype and the degree of dysplasia, which will define the risk of malignant progression and allow the proper patient selection for surgery (9). When the surgeon approaches a patient with pancreatic cystic lesions, clinical management starts with mucinous vs. nonmucinous cyst distinction and afterward with low versus high-risk definition $(9,10)$. Currently, Fukuoka guidelines represent the gold standard in daily practice, with the definition of main duct and branch duct subtypes, and cysts with "worrisome features" (10). Non-neoplastic cysts do not require surgery, low-risk cysts can be managed by surveillance and in high-risk cysts surgery is the treatment of choice (9).

Radiological evaluations are not specific enough for malignancy, and the classification of branch duct type (pancreatic cysts bigger than $5 \mathrm{~mm}$ and with communication with the pancreatic main duct) and main duct type (segmental or diffuse dilation of the main pancreatic duct, $>5 \mathrm{~mm}$, without causes for obstruction) IPMN has limited value (11). There is a higher risk of transformation to pancreatic ductal adenocarcinoma (PDAC) in main duct IPMN, and cystic fluid analysis associated with cytology is advised $(7,9,10,12)$.

\section{Cytology approach and molecular markers}

\section{Cytology approach}

In order to develop an individualized approach of these patients, a precise and early diagnosis should be rendered. Endoscopic ultrasound (EUS) with contrast enhancement is a powerful tool for the differential diagnosis of pancreatic cystic lesions, especially when associated with fine-needle aspiration (FNA) (13). This is of upmost importance, since despite being stated in several consensuses reports (14-16) that proof of malignancy from the biopsy is not needed when clinical suspicion of malignancy is high $(14,15,17)$, in up to $10 \%$ of the resected specimens the "pancreatic cancer" is another type of lesions such as chronic and autoimmune pancreatitis (18). Therefore, taking in consideration the morbimortality of pancreatic surgery, the correct differential diagnosis is fundamental for patient management.

In the diagnosis of cystic lesions of the pancreas, cytology has a pivotal role. EUS-FNA approach is safe, with high diagnostic accuracy with low seeding risk (usually the seeding track is removed with the surgical specimen), and can be performed on a pure cystic lesion or in the solid component in order to assess IPMN associated carcinoma (19).

Cytology is an accurate method to establish whether a cyst is mucinous or non-mucinous and to evaluate the degree of atypia (20). From a historical perspective, mucus-producing cystic neoplasms are considered rare; however, their incidence has been increasing, mainly due to increased detection by widespread use of imaging diagnostic tools $(11,20)$.

Currently, the classification is based on the Papanicolaou Society of Cytopathology with the following categories: 1) nondiagnostic; 2) negative for malignancy; 3) atypical; 4) neoplastic; 5) suspicious for malignancy; and 6) malignant (21). In this cytological classification, IPMN with low or high-grade dysplasia is classified as "neoplastic", and shows a very good correlation with risk of malignancy - up to $94.9 \%$ of specificity (21).

Thick and gelatinous mucous is the diagnostic hallmark of mucinous cystic lesions and easily perceived of evidenced by PAS-diastase stain (20); however, it is not related to lesion grade (22). The degree of atypia may be difficult to assess since the majority of the samples are pauci-cellular, but three-dimensional clusters with hyperchromasia are predictors of at least moderate dysplasia, while parachromatin clearing and necrosis foresee invasive carcinoma $(20,22)$ (Fig. 1).

Ancillary studies may prove useful in assessing malignancy in IPMNs with the expression of insulin-like growth factor-II messenger ribonucleic acid-binding protein 3 (IMP3)(23) and P53 expression (24). The main differential diagnosis problem is posed by gastrointestinal contamination. While duodenal contamination is rather easy to discard (20), gastric contamination may prove to be more complicated; in this setting, immunostaining with B72.3 is a valuable ally revealing diffuse cytoplasmic staining in the neoplastic cells $(25,26)$.

\section{Molecular markers}

EUS-FNA also represents a valuable tool for cyst fluid biochemical and molecular analysis $(11,27,28)$. A fluid CEA level $\geq 192 \mathrm{ng} / \mathrm{mL}$ has been reported as being accurate for the classification of the cyst as mucinous $(9,21)$. When the value of CEA is superior to $800 \mathrm{ng} / \mathrm{mL}$ with amylase level $>250 \mathrm{U} / \mathrm{L}$ the possibility of being a pseudocyst in unlikely (21). The combination of molecular studies, mainly GNAS and KRAS testing has been reported to have an $84 \%$ sensibility 


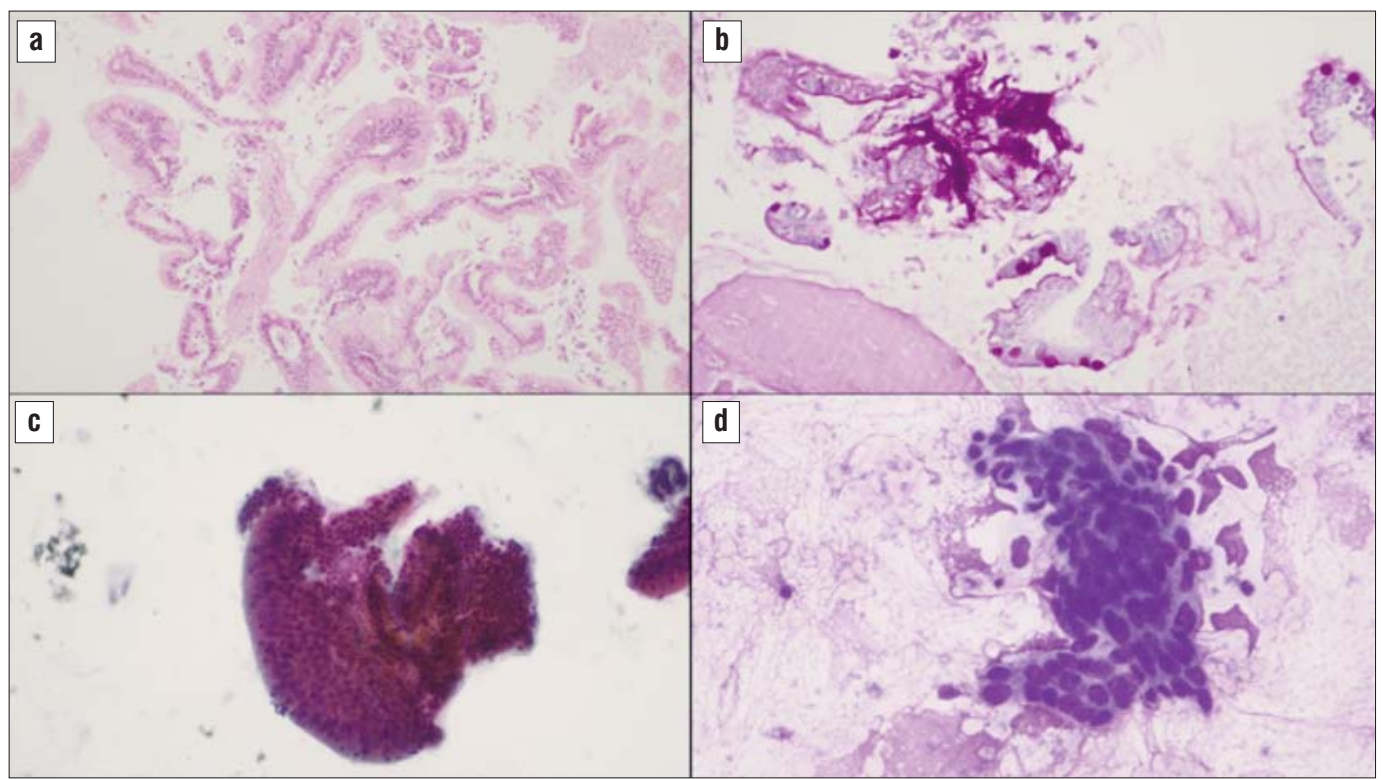

Figure 1 - Cytological features of intraductal papillary mucinous neoplasms: Papillary architecture of the lesion is promptly identified, with low-grade dysplasia - cell block preparation, H\&E 100x (a); neutral mucin component can be highlighted by special stain - cell block preparation, PAS-diastase 200x (b); a threedimensional cluster with nuclear hyperchromasia representing low-grade dysplasia - conventional smear, H\&E 200x (c); another three-dimensional cluster with high-grade dysplasia and parachromatin clearing, which had an invasive carcinoma in the surgical specimen - conventional smear, Giemsa 400x (d).

and $98 \%$ specificity for IMPN diagnosis (21).

GNAS is an oncogene located at the long arm of chromosome 20, and it represents an important tool for the IPMNs diagnosis since of all the markers available, GNAS mutations have been appointed as the most precise in the differential diagnosis and are found exclusively in IPMNs $(7,12,28)$. The most common GNAS mutation occurs at codon 201 and it is found in up to $60 \%$ of IPMNs (28). Some studies have linked GNAS mutations to be more common in the intestinal subtype IPMN, and despite a more prevalent mutation rate of GNAS mutations in more advanced lesions, there has not been a solid association with concomitant PDAC and grade of dysplasia $(7,9,28)$.

KRAS gene is an oncogene located on the short arm of chromosome 12 which has been reported to associate with IPMN with variable frequencies $38-100 \%$ (28). KRAS mutation is considered to be an early event in IPMN's malignant transformation (29). However, there is no significant association between KRAS mutations and the level of dysplasia (30). The possibility of discovering KRAS mutations in pancreatic juice, peripheral blood, and surgical specimens has turned this marker into a very promising diagnostic tool $(28,31)$. Nevertheless, the testing of pancreatic juice must be interpreted with caution since KRAS mutations have been reported in mucin hypersecreting conditions as well as in chronic pancreatitis $(28,32)$. Of note, KRAS mutations have been reported in the majority of pancreatobiliary IPMN subtypes (30).

In the same pathway, mutations in BRAF - a serine/ threonine kinase located immediately downstream in the RAS signaling - have been described, but in lower frequencies - up to 3\% (33). Despite their low frequency, the induced changes in the MAPK pathway, especially if associated with a RAS mutation, are expected to play an important role in IPMN malignant transformation, and potentially in an accelerated progression $(28,33,34)$.

The role of the PI3K/Akt pathway has also been considered in IPMN pathogenesis. This pathway encompasses a large family of kinases with a role in cellular proliferation, differentiation, and survival, however, mutations in PI3K/Akt are only present in about $11 \%$ and seem to be a late event $(28,33)$. P53 is an important tumor suppressor gene, located at chromosome 17 widely known as the guardian of the genome, playing key roles in cell cycle arrest, repair of DNA damage and regulation of senescence (35). In IPMN carcinogenesis, p53 mutations have been described as a late event, with inactivation in almost all invasive tumors associated with IPMN $(28,36)$; when associated with loss of heterozygosity in p16, they are present in all invasive tumors (37). Mutations in the cyclin-dependent kinase inhibitor 2A/p16 (CDKN2A) gene which encodes $p 16$, resulting in its loss of function 
and accelerated cellular growth are thus a powerful tool for detecting malignant transformation $(38,39)$. Therefore, additional testing for P53/PIK3CA/PTEN can have value in predicting advanced neoplasia $(21,23,40)$.

Recently, several other genes have been implicated in IPMN carcinogenesis.

Hedgehog pathway is controlled by proteins responsible for the regulation of tissue and organ development, encompassing three major genes desert hedgehog, Indian hedgehog, and Sonic Hedgehog (41); the latter is the best characterized and is reported in a higher percentage of invasive carcinomas and malignant IPMNs (42) and in the pancreatobiliary IPMN subtype (42). Interestingly, Sonic Hedgehog expression has been reported in higher expression in stromal cells in malignant IPMNs (42) and pancreatic juice from patients with IPMN but not in "normal" pancreatic juice, therefore having a major potential to distinguish between IPMN and chronic pancreatitis (43).

Mutations in telomerase reverse transcriptase (TERT) a gene on chromosome 5, are able to restore telomeric function, overcoming the so-called telomere crisis, and have been described in higher expression in malignant IPMNs (44). Serine/threonine kinase 11 (STK11) gene, tumor suppressor located at chromosome 19, has been associated with IPMN and PDAC, especially in patients with Peutz-Jeghers syndrome (45) and Brahma-related gene 1 (BRG1), encoded on chromosome 19 and associated with the SWI/ SNF chromatin remodeling complex, has been reported in IPMNs, with higher frequencies in high-grade lesions (46).

In addition to mutations, gene methylation can also have a pivotal role in IPMN development and carcinogenesis (28). Hypermethylation is important in development (47), but aberrant hypermethylation and subsequent silencing of tumor suppressing genes is one of the major causes of carcinogenesis (48). In IPMN, hypermethylation is evident in more than $80 \%$ of cases (49) and more frequently in genes with wellcharacterized functions in tumor suppression - p16, APC, E-cadherin, MLH1, and MGMT (50). The number of methylated genes is higher in high-grade lesions (51) and more genes have been reported with a significant difference between lower and higher grade lesions such as TFPI-2, BNIP3, and PTCHD2, among others (28, $51,52)$. Henceforth the evaluation of methylated DNA in pancreatic juice could be useful for pre-surgical evaluation of non-invasive and invasive lesions (49).

MlcroRNAs (miRNAs) are small molecules which functions as gene expression regulators. Their mechanism of action is by binding messenger RNA with its posterior degradation or translational inhibition (53). This effect may be important for cellular stability and proliferation control as well as apoptosis (53), and they can induce oncogenes expression or tumoral suppressor genes inhibition associated to pancreatic carcinogenesis (54-57). Of all miRNAs reported in the literature, miRNA-21, which inhibits PTEN and consequently activate the Akt signaling pathway, and miRNA-155, which represses a pro-apoptotic protein (TP53INP1), are significantly upregulated in noninvasive IPMN and may achieve higher levels in patients with invasive component $(55,58,59)$. The miRNA-21 has also been linked with chemotherapy resistance, worse overall survival and shorter disease-free survival, prompting it as a precious prognostic biomarker of worse prognosis (60-63). Conversely, miRNA-101- a downregulator of EZH2 - has emerged as a good prognostic biomarker (58). Low levels of miRNA-101 have been associated with invasive tumors and higher levels with non-invasive IPMNs $(56,57,63)$.

Finally, the members of the S100 protein have been implied in IPMN development and PDAC carcinogenesis $(64,65)$. The members of this family have different cellular locations and besides functions in the $\mathrm{Ca}^{2+}$ signaling network, they have a role in cell cycle progression, proliferation and transcriptomic activity (66). Of the more than 100 members of this family, some have been associated with pancreatic carcinogenesis, especially the S100p and S100A4 $(64,67)$. Both have higher levels in advanced IPMNs and in patients with invasive disease (28) and very interestingly S100P is measurable in pancreatic juice and its levels may allow discriminating neoplastic disease from its mimics, namely chronic pancreatitis $(68,69)$.

The potential for this type of testing is increasing and nowadays they are possible in tissue and fluid cyst and feasible in most of Pathology Departments via Polymerase Chain Reaction (PCR) and Next Generation Sequencing (NGS) techniques.

The duodenal fluid has also been evaluated as a possible method for IPMN diagnosis and patient stratification since the duodenum is in direct contact with pancreatic juice, which contains the neoplastic cells. Since endoscopic retrograde pancreatography is not recommended by guidelines, the evaluation of duodenal fluid after secretin stimulation seems an easy and feasible approach - in the scenario GNAS mutations have been described in a consistent manner as in the pancreatic tissue (7). Finally, in the liquid biopsy era the analysis of circulating DNA is a promising method and some research has been made in that direction; 
however, the low concordance in the resected specimens (56.3\%) is still far away from the appropriate (7).

\section{Gross examination of surgical specimens}

The macroscopic examination usually shows a gross visible lesion, normally a dilation of the main duct or one or more cysts with communication to the pancreatic ductal system. A typical sign is mucin excretion from a patulous Ampulla of Vater (AFIP), which should raise suspicion for IPMN; this sign may be also appreciable in endoscopy examination $(70,71)$.

The main pancreatic duct should be identified for lesion classification and its largest diameter should be recorded (72). Measuring the distance between IPMN and invasive carcinoma as well as sampling the tissue between the two components is highly recommended (73). The correct size of the lesion may prove of utmost importance in future risk assessment and would also allow correlating with the radiologic findings $(72,74-76)$, however assessing the correct size of a cystic lesion may be challenging since cysts may rupture in surgical procedure or gross specimen manipulation (72). Recent recommendations suggest that if the cyst size on gross examination is inferior to the one reported on radiology, the latter should be used on the pathology report along with a commentary that justifies the use of that measure (72). In the case of unifocal but multicystic lesions, the overall size of the collections of locules and the dimension of the largest should be reported, while in multifocal lesions the largest focus dimension should be assessed (72).

IPMNs are usually cystic and any solid component should raise awareness for invasive carcinoma (77). The measurement of this component is also important since the may be overlooked or underestimated by radiology
(72) and is fundamental for TNM classification (1).

The sampling of the lesions is fundamental for assessment IPMN grade of dysplasia and association with invasive carcinoma, therefore representing the major factor of prognosis in the patients with IPMN $(1,72,78,79)$. An IPMN associated carcinoma may only be excluded after complete evaluation and sampling of the lesion and the pancreatic tissue in the vicinity (72) - which may harbor invasive and subtle carcinomas as well as neoplastic changes - a practice well implemented at our institution.

The macroscopic morphology of IPMN will depend on its location (77). Main duct type IPMNs are located in the main pancreatic duct. External pancreatic surface may be globous and after sectioning the main duct exhibit dilation and lumen filled with mucin and papillary/villous projections (80) (Fig. 2 and Fig. 3). The majority of the main duct type IPMN are located in the head of the pancreas, but up to one third may be located in the body or tail. Due to main duct obstruction, the remaining pancreas usually shows obstructive chronic pancreatitis (77).

Branch duct type are found in the pancreatic secondary branches and have the appearance of a mucinous cyst (77) (Fig. 4). Since they usually do not induce obstruction, the remaining pancreas seems unremarkable81. This subtype is more common in the pancreatic head and uncinated process but up to $40 \%$ may be multifocal $(77,80)$.

Mixed or combined type affects both the primary and secondary branches of the pancreatic ductal system (77). Clinical and biological characteristics are similar to the main duct type, so it is assumed the mixed type may represent an extension of the main duct type to the secondary ducts (82).

Unusual macroscopic features of IPMN have also

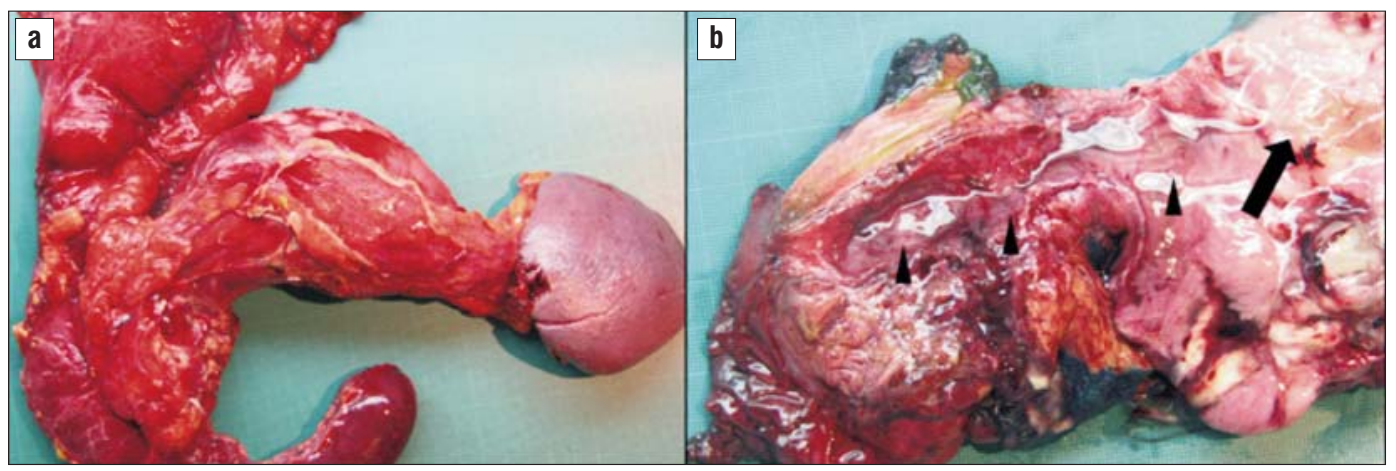

Figure 2 - Gross examination of a main duct intraductal papillary mucinous neoplasm: a cephalic duodenopancreatectomy with globous pancreas (a). After sectioning (b) there was a cystic lesion in the main duct with thick mucinous content (black arrowheads); the lining of the lesion was smooth and focally with vegetations (black arrow) 


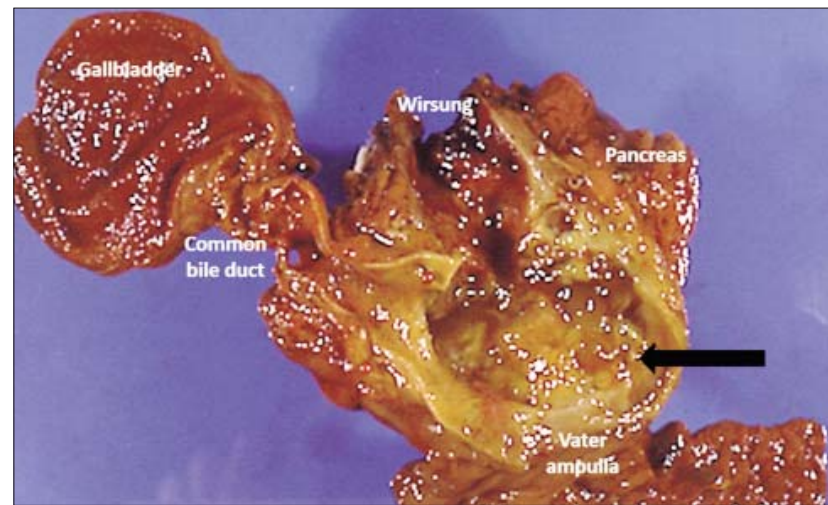

Figure 3 - Surgical specimen of a main duct intraductal papillary mucinous neoplasm - marked dilation of the Wirsung channel up to $6 \mathrm{~cm}$ in the periampullary region, with mucinous content and vegetations (black arrow)

been described and include protrusion out of the ampulla (83), fistula to other organs (duodenum, small and large bowel, stomach) (84-87), mucin spilling to the peritoneum with pseudomyxoma peritoneum $(88,89)$ and pancreatic calcification $(90,91)$. Fistula formation was initially thought to be in association with malignant IPMN, but some cases of non-malignant IPMN with fistula have been reported (77).

\section{Microscopic evaluation, classification and differential diagnosis}

Microscopic examination, in the majority of situations start with a frozen section evaluation of the pancreatic surgical margin. Frozen examination of pancreatic surgical margin may be required by the surgeon, especially in patients with suspicion of invasive cancer; this evaluation can detect high-grade dysplasia or invasive tumor however it may miss discontinuous lesions that may be responsible for recurrence (11).
The main issue is the assessment of high-grade dysplasia/invasive carcinoma, since low-grade dysplasia does not require additional surgery; however, since low-grade PanINs are indistinguishable from low-grade IPMNs of the gastric type, no effort should be performed to discriminate between these entities and the focus should be on the evaluation of high-grade dysplasia/invasive carcinoma (10). High-grade dysplasia or invasive neoplasm should prompt for surgical resection extension, sometimes necessitating total pancreatectomy $(11,92)$.

According to the recent WHO classification, IPMNs can be classified as pancreatic, gastric and intestinal subtypes (1). In the past, there was a fourth subtype, the oncocytic, nowadays reported as a different histological entity - intraductal oncocytic papillary neoplasm due to its unique architecture, lower association with PDAC and different molecular profile with ARHGAP26, ASXL1, EPHA8 and ERBB4 mutations instead of the more common mutations in IPMN described previously in this manuscript $(1,8)$.

At histological evaluation, IPMNs correspond to the intraductal proliferation of mucin-producing cells of columnar morphology, which may be flat or forming papillae - microscopic or grossly evident (1). The grade of dysplasia should be granted according to the highest degree and classified as low-grade or high-grade, with the previously designed intermediate-grade dysplasia now included in the low-grade (73). Low-grade lesions exhibit mild to moderate cellular atypia, normally without mitoses and may not have papillary projections, while high-grade IPMNs display irregular and branching papillae with severe atypia, nuclear stratification, pleomorphism, prominent nucleoli and easily assessed mitotic activity $(1,93)$.

After dysplasia assessment, one should classify the IPMN into one of the three major subtypes, according

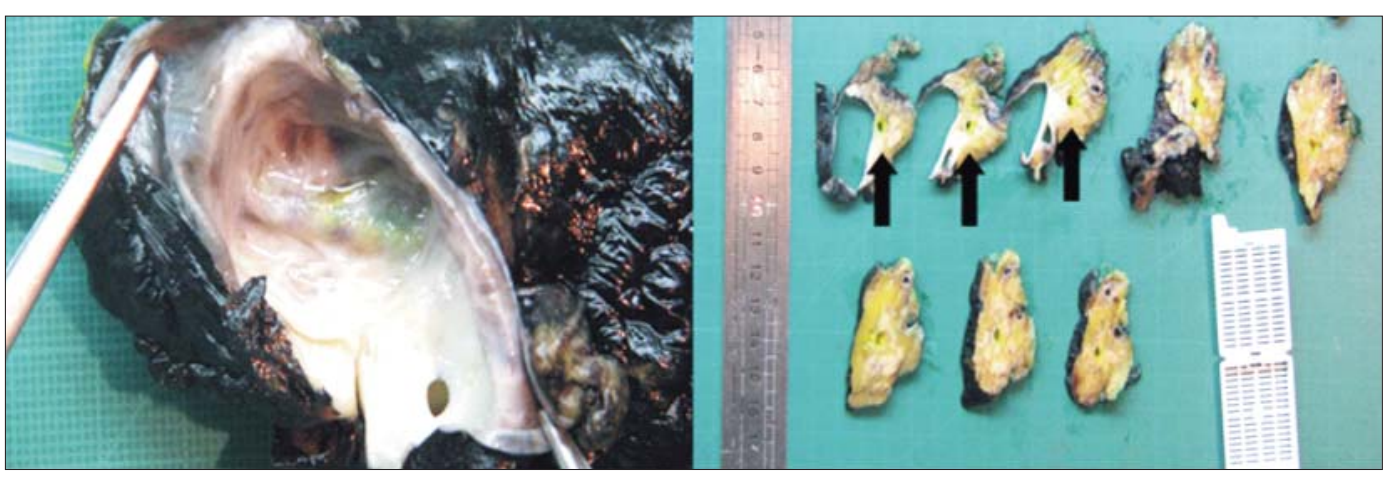

Figure 4 - Gross examination of a branch-duct intraductal papillary mucinous neoplasm. On the left side a cyst accidentally opened during surgery, with smooth inner surface. On the right side, on cut section it is easily appreciable that the cyst does not have communication with the Wirsung (black arrows) 
to the pattern of cellular differentiation - gastric, intestinal and pancreatobilliary (1). This is usually based on morphology and, especially on immunohistochemical profile determination - MUC1, MUC2, MUC5AC and MUC6; CDX2 and CK20 may have an additional role on the intestinal subtype $(1,94)$. This classification is important since the three subtypes have different clinical presentations and, of utmost importance, different prognosis.

Gastric-type IPMNs are the most common and usually of branch ducts. The cells are tall and columnar with basal nucleus and mucinous cytoplasm, with an apical mucin cap, similar to the gastric foveolar epithelium (93) (Fig. 5). Scattered goblet cells may also be detected. Usually, gastric-type IPMN has a low-grade dysplasia but some cases may display high-grade dysplasia and invasive adenocarcinoma of conventional type $(1,16)$. Gastric-type IPMN is less prone to develop an invasive component (93) at the phenotypic level, gastric type IPMNs usually have a diffuse expression of MUC5AC and MUC6, without expression of MUC1 and
MUC2, although in the latter focal expression and on scattered cells is acceptable (77). As mimickers of gastric mucosa, in gastric type IPMNs expression should be more intense for MUC5AC in the superficial component and for MUC6 in the basal counterpart (95).

Intestinal-type IPMN is the second more common form, presenting typically in the main duct, with villous intestinal epithelium, forming papillae with enlarged and elongated nuclei and a variable amount of mucin, resembling intestinal mucosa (93) (Fig. 6). Intestinaltype IPMN commonly has high-grade dysplasia and when associated with invasive carcinoma it usually are of mucinous subtype with a better prognosis than conventional type $(1,16,77)$. Mucin profiling should reveal diffuse expression of MUC2 and MUC5AC without expression for MUC1 and MUC6 (77).

Pancreatobiliary-type represents the less common subtype. Typically, it develops in the main duct and the papillae are more complex, branching arborizing and interconnected, lined by cuboid cells with amphiphilic cytoplasm, enlarged nucleus, and prominent nucleoli

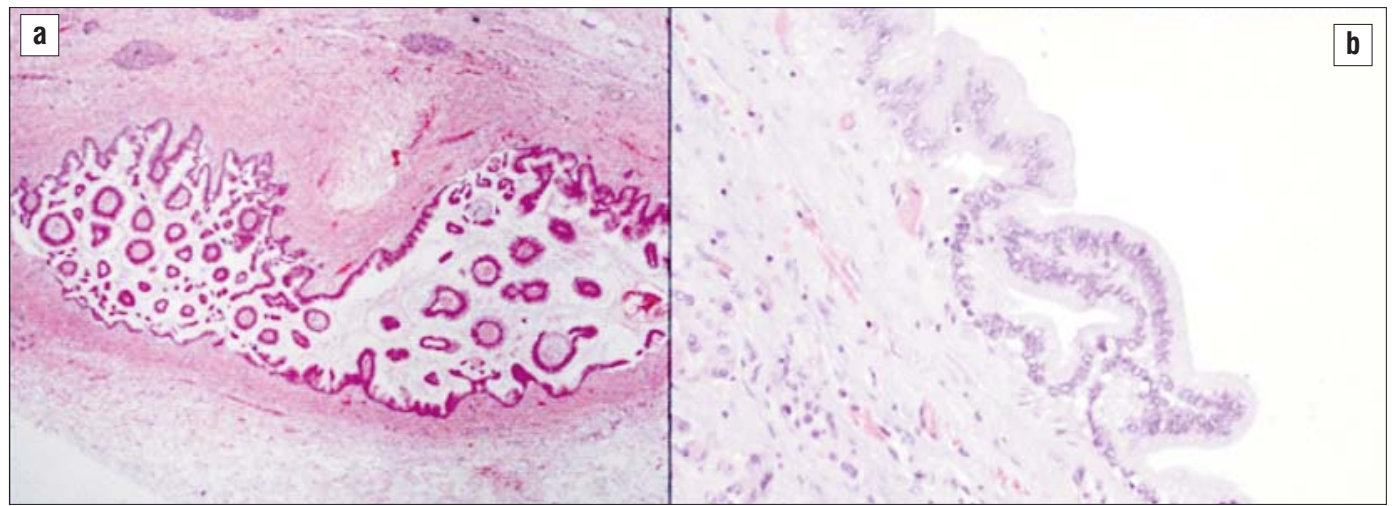

Figure 5 - Gastric type intraductal papillary mucinous neoplasm: a cystic lesion lined by flat and papillary epithelium (a, H\&E 40x). The cells are cylindrical, with basal located nuclei and morphologically resemble gastric foveolar epithelium with low-grade dysplasia (b, H\&E 200x)

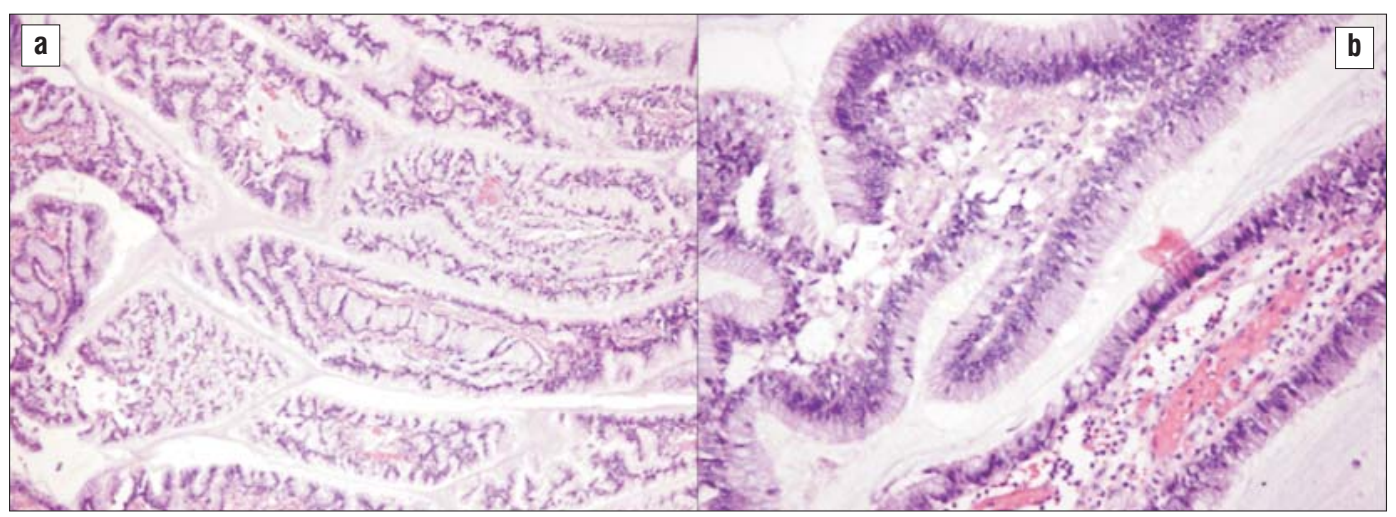

Figure 6 - An intestinal type intraductal papillary mucinous neoplasm with a branching and villiform pattern (a, H\&E 40x). The papillae were lined by columnar cells with pseudostratified nuclei similar to colonic adenomas with low-grade dysplasia (b, H\&E 200x). 


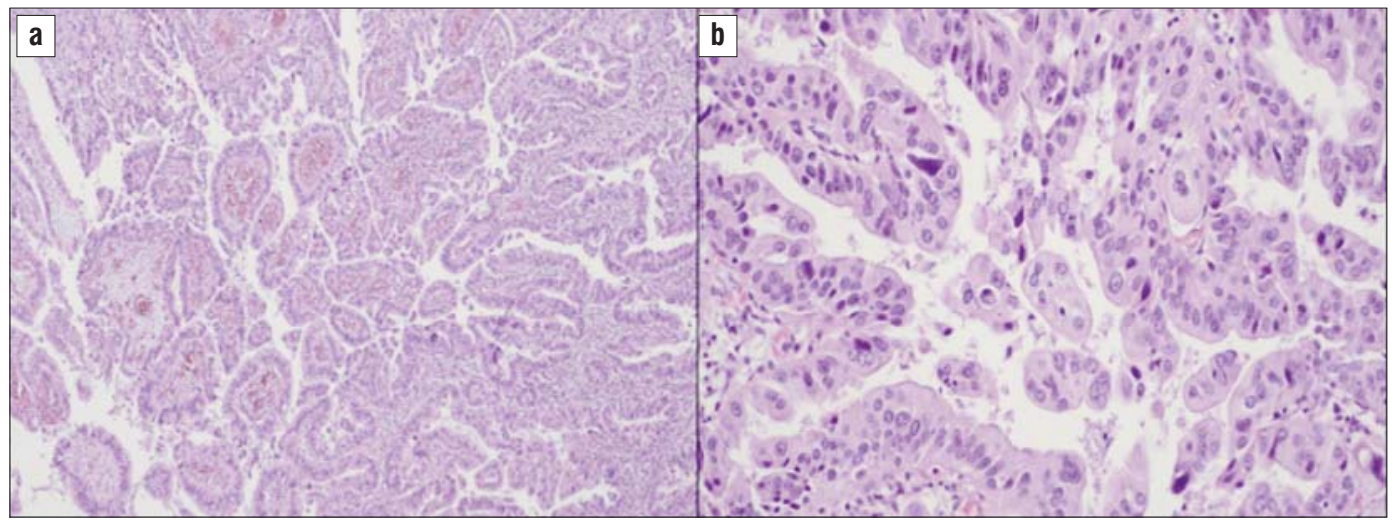

Figure 7 - Biliary type intraductal papillary mucinous neoplasm: complex and branching papillae are usually a feature (a, H\&E 40x) and are lined by cuboidal to columnar cells with eosinophilic cytoplasm and marked nuclear atypia and hyperchromasia - high-grade dysplasia (b, H\&E 200x)

(Fig. 7). Mucin is minimal (93). Most of the pancreatobiliary-type are high-grade lesions 1 . On this subtype, it is expected an expression of MUC1 and MUC5AC, without MUC2 and MUC6, although there can be focal expression for MUC6 (77).

The different immunoprofiles are summarized in Table 1.

Besides the role in subtyping the IPMNs, the expression of human mucins have been associated with invasive IPMNs with higher expression of MUC1 and MUC2 in advanced lesions $(28,96,97)$. MUC4 expression, not present in normal pancreas, may reflect ErbB-2 activation and has also been linked to advanced and invasive IPMNs and could be a potential biomarker, especially since it can be detected in the cystic fluid (98-100).

\section{Differential diagnosis}

The main pathological differential diagnosis of IPMN is with MCN and pancreatic intraepithelial neoplasia (PanIN) (1). MCN does not have a communication with the pancreatic ductal system at gross examination, and are more common in pancreatic body/tail and in women $(1,93)$. From an histological perspective, MCN is lined by mucinous columnar epithelium, underneath with an easily perceptive spindle cell stroma of ovarian type $(1,93)$. On a cytological basis, the epithelium of IPMN and MCN are very similar and the ovarian stroma is necessary for the correct diagnosis - as cytology approaches cannot discern between these two entities (93). MCN is also linked to PDAC development (1). The main features useful for differential diagnosis are listed in Table 2.

IPMN and PanIN distinction may be particularly difficult. Size usually provides a very helpful tool since PanIN is usually under $0.5 \mathrm{~cm}$ and IPMNs are over $1 \mathrm{~cm}$ (73). However, small cysts with sizes between 0.5 and $1 \mathrm{~cm}$ present a borderline situation. Differentiation of cells may be an approach since almost all PanINs have gastric differentiation and IPMNs may exhibit intestinal and pancreatobiliary, but small gastric-type IPMNs may be virtually indistinguishable from PanINs (73). IPMNs would invariably start with smaller lesions that will progress with time and be characterized as IPMNs due to size; these lesions with $0.5-1 \mathrm{~cm}$ in size and gastric phenotype may be categorized under a descriptive lesion - intraductal low-grade neoplasm of gastric type 73 or use the term "incipient IPMN" (72). In this context, GNAS mutations have been reported in gastric-type IPMNs and absent in PanINs and can provide differential diagnosis $(101,102)$.

Table 1 - Different immunoprofiles of the intraductal papillary mucinous neoplasm (IPMN) subtypes. Adapted from: WHO Classification of Tumours Editorial Board. Digestive system tumours. Lyon (France): International Agency for Research on Cancer, 2019

\begin{tabular}{lcccccc}
\hline IPMN subtype & CK7/CK19 & MUC1/EMA & MUC2 & MUC5AC & MUC6 & CK20/CDX2 \\
\hline Gastric & + & - & - & + & +- & - \\
\hline Intestinal & + & - & + & - & - & + \\
\hdashline Pancreatobiliary & + & + & - & + & + & - \\
\hline
\end{tabular}


Table 2 - Differential diagnosis of intraductal papillary mucinous neoplasm. IPMN - intraductal papillary mucinous neoplasm; MCN - mucinous cystic neoplasm.

Adapted from: WHO Classification of Tumours Editorial Board. Digestive system tumours. Lyon (France): International Agency for Research on Cancer, 2019

\begin{tabular}{lcc}
\hline & \multicolumn{1}{c}{ IPMN } & MCN \\
\hline Gender & Male (in some countries) & Female \\
\hline Age & $6^{\text {th }}-7^{\text {th }}$ decade & $5^{\text {th }}$ decade \\
\hline Localization & Pancreatic head & Pancreatic body and tail \\
\hdashline Features & Ductal system ectasia; thick mucin & Cystic lesion; Ovarian-like stroma \\
\hdashline Communication with ductal system $\quad$ Yes & No \\
\hline
\end{tabular}

The remaining intraductal lesions of the pancreas have distinct morphological features and are easily identified: Pancreatic intraductal oncocytin papillary neoplasm, once a part of IPMN, has different molecular alterations and on a morphological level exhibits complex and arborizing papillae lined by oncocytic cells, sometimes in a cribriform pattern; the pancreatic intraductal tubulopapillary neoplasm has intratubular growth, but its pattern is predominantly tubular and without mucin production (1)

\section{Prognosis}

After the correct diagnosis is established, the other main characteristics that should be stated in the pathological report are staging and grading of the invasive component (if present) and evaluation of surgical margin status (72).

The surgical margin may be assessed in the frozen section, as stated before, or only after paraffin embedding $(72,103)$. This is extremely important since it may stratify patients with a higher risk of disease progression/relapse, even in patients without noninvasive IPMNs $(28,104)$. This so-called local progression, with increased risk of developing an invasive carcinoma, represents a clinical problem (104). The most well-established factor for higher risk of disease progression is high-grade dysplasia at the margin (104-109). Regarding negative surgical margins or low-grade dysplasia, several studies have proposed reasons for disease progression: monoclonal lesions, with high-grade dysplasia or invasive carcinoma, suggesting a diffuse and unstable ductal epithelium is the most accepted theory, especially in main duct IPMNs (110); while in the branch duct IPMNs clonally independent and multifocal lesions is the most probable mechanism (111). Irrespective of the origin of lesion in the remnant pancreas (recurrence or de novo), a close clinical follow-up is justified for patients with any degree of dysplasia at the surgical margin (73).

The mechanisms of IPMN progression to invasive carcinoma are not completely unveiled. In a recent discovery, genetic analysis by Omori et al. (112) established three distinct models of carcinogenesis: 1) a sequential model with low-grade, high-grade dysplasia and invasive carcinoma sequence, with driver mutations shared between IMPN and carcinoma; 2) a branch-off model, where IPMN and adjacent tumors share KRAS mutations but have different GNAS mutations; 3) a de novo model where no driver mutations where shared by IMPN and invasive carcinomas. The current clinical concept only provides evidence for the sequential subtype (16). The knowledge of two different pathways - the branch off and the de novo, which occur in about two-third of patients with IPMN after surgical resection - provides a major insight into the pathology of IPMNs that are multicentric/synchronous lesions and not a locoregional event and prompts for establishment of new surveillance guidelines (112).

\section{CONCLUSION}

In summary, IPMNs are complex neoplasms from the genetic standpoint. For their correct classification, it is of upmost importance the coordination of radiologic, gross examination and microscopic data evaluations. The pathologist plays a pivotal role in the approach of IPMNs and cytology with resort to ancillary markers, as well as molecular studies of cyst content may lead to a different patient management. Thus, it is critically important to correctly classify the IPMNs. Assessment of surgical margin status and invasive component should be mandatory. Due to the complexity of this entity, it is recommended that expert physicians manage IPMNs in reference centers. 


\section{Conflict of interest}

\section{All author declare that they have no conflict of interest.}

\section{REFERENCES}

1. WHO Classification of Tumours Editorial Board. Digestive system tumours. Lyon (France): International Agency for Research on Cancer, 2019.

2. Khan S, Sclabas G, Reid-Lombardo K.M. Population-based epidemiology, risk factors and screening of intraductal papillary mucinous neoplasm patients. World J Gastrointest Surg. 2010; 2(10):314-8

3. Laurent L, Vullierme M-P, Rebours V, Maire F, Hentic O, Francoz C et al. Estimation of the prevalence of intraductal papillary mucinous neoplasm of the pancreas in the French population through patients waiting for liver transplantation. United European Gastroenterol J. 2017;5(4);499-503

4. Ingkakul T, Warshaw AL, Fernández-Del Castillo C. Epidemiology of intraductal papillary mucinous neoplasms of the pancreas: sex differences between 3 geographic regions. Pancreas. 2011;40: 779-80

5. Xiao S-Y. Intraductal Papillary Mucinous Neoplasm of the Pancreas: An Update. Scientifica (Cairo). 2012;1-20.

6. Flanagan MR, Jayaraj A, Xiong W, Yeh MM, Raskind WH. Pancreatic intraductal papillary mucinous neoplasm in a patient with Lynch syndrome. World J Gastroenterol. 2015;21(9):2820-5.

7. Ohtsuka T, Tomosugi T, Kimura R, Nakamura S, Miyasaka Y. Clinica assessment of the GNAS mutation status in patients with intraductal papillary mucinous neoplasm of the pancreas. Surg. Today. 2019;49(11):887-893.

8. Wang Y-Z, Lu J, Jiang B-L, Guo J-C. Intraductal oncocytic papillary neoplasm of the pancreas: A systematic review. Pancreatology. 2019;19(6):858-865

9. Levink I, Bruno M, Cahen D. Management of Intraductal Papillary Mucinous Neoplasms: Controversies in Guidelines and Future Perspectives. Curr. Treat. Options Gastroenterol. 2018;16(3): 316-332.

10. Tanaka M, Fernández-Del Castillo C, Kamisawa T, Young Jang J, Levy $P$, Ohtsuka $T$, et al. Revisions of international consensus Fukuoka guidelines for the management of IPMN of the pancreas. Pancreatology. 2017;17(5):738-753.

11. Del Chiaro, M. et al. European evidence-based guidelines on pancreatic cystic neoplasms. Gut. 2018;67(5):789-804.

12. Volckmar A-L, Endris V, Gaida MM, Leichsenring J, Stögbauer F, Allgäuer $M$, et al. Next generation sequencing of the cellular and liquid fraction of pancreatic cyst fluid supports discrimination of IPMN from pseudocysts and reveals cases with multiple mutated driver clones: First findings from the prospective ZYSTEUS biomarker study. Genes. Genes Chromosomes Cancer. 2019;58(1):3-11.

13. Yoshida T, Yamashita Y, Kitano M. Endoscopic Ultrasound for Early Diagnosis of Pancreatic Cancer. Diagnostics (Basel, Switzerland) 2019;9(3).

14. Ducreux M, Sa Cuhna A, Caramella C, Hollebecque A, Burtin P, Goéré $D$, et al. Cancer of the pancreas: ESMO Clinical Practice Guidelines for diagnosis, treatment and follow-up. Ann. Oncol. 2015; 26:v56-v68.

15. Tempero MA, Malafa MP, Al-Hawary M, Asbun H, Bain A, Behrman SW, et al. Pancreatic Adenocarcinoma, Version 2.2017, NCCN Clinical Practice Guidelines in Oncology. (Referenced with permission from the NCCN Clinical Practice Guidelines in Oncology (NCCN Guidelines $($ ) for Guideline Name V.2.2017. (C) National Comprehensive Cancer Ne. J Natl Compr Canc Netw. 2017;15(8): 1028-1061.

16. Tanaka M, Fernández-Del Castillo C, Kamisawa T, Young Jang J, Levy $\mathrm{P}$, Ohtsuka T, et al. Revisions of international consensus Fukuoka guidelines for the management of IPMN of the pancreas. Pancreatology. 2017;17(5):738-753.
17. Asbun HJ, Conlon K, Fernandez-Cruz L, Friess H, Shrikhande SV, Adham $\mathrm{M}$, et al. When to perform a pancreatoduodenectomy in the absence of positive histology? A consensus statement by the International Study Group of Pancreatic Surgery. Surgery. 2014; 155(5):887-92.

18. Van Heerde MJ, Biermann K, Zondervan PE, Kazemier G, van Eijck $\mathrm{CHJ}$, Pek $\mathrm{C}$,et al. Prevalence of autoimmune pancreatitis and other benign disorders in pancreatoduodenectomy for presumed malignancy of the pancreatic head. Dig Dis Sci. 2012;57(9): 2458-2465.

19. Suzuki R, Irie H, Takagi T, Sugimoto M, Konno N, Sato Y, et al. Prognostic influence of endoscopic ultrasound-guided fine needle aspiration in IPMN-derived invasive adenocarcinoma. BMC Cancer. 2018;18(1):974

20. Bellizzi, A. M. \& Stelow, E. B. Pancreatic cytopathology: a practical approach and review. Arch Pathol Lab Med. 2009;133(3):388-404.

21. Smith AL, Abdul-Karim FW, Goyal A. Cytologic categorization of pancreatic neoplastic mucinous cysts with an assessment of the risk of malignancy: A retrospective study based on the Papanicolaou Society of Cytopathology guidelines. Cancer Cytopathol. 2016; 124(4):285-93.

22. Michaels PJ, Brachtel EF, Bounds BC, Brugge WR, Pitman MB. Intraductal papillary mucinous neoplasm of the pancreas: cytologic features predict histologic grade. Cancer. 2006;108(3):163-73.

23. Senoo J, Mikata R, Kishimoto T, Hayashi M, Kusakabe Y, Yasui S, et al. Immunohistochemical analysis of IMP3 and p53 expression in endoscopic ultrasound-guided fine needle aspiration and resected specimens of pancreatic diseases. Pancreatology. 2018;18(2): 176-183.

24. Khalid A. Differentiating Neoplastic From Benign Lesions of the Pancreas: Translational Techniques. YJCGH 7. Clin Gastroenterol Hepatol. 2009;7(11 Suppl):S55-8.

25. Nagle JA, Wilbur DC, Pitman MB. Cytomorphology of gastric and duodenal epithelium and reactivity to B72.3: a baseline for comparison to pancreatic lesions aspirated by EUS-FNAB. Diagn. Cytopathol. 2005;33(6):381-6.

26. Nawgiri RS, Nagle JA, Wilbur DC, Pitman MB. Cytomorphology and B72.3 labeling of benign and malignant ductal epithelium in pancreatic lesions compared to gastrointestinal epithelium. Diagn. Cytopathol. 2007;35(5)300-5.

27. Tag-Adeen M, Ozawa E, Ogihara K, Iwatsu S, Akazawa Y, Ohnita K, et al. The role of pancreatic juice cytology in the diagnosis of pancreatic intraductal papillary mucinous neoplasm. Rev Esp Enferm Dig. 2018;110(12):775-781.

28. Paini M, Crippa S, Partelli S, Scopelliti F, Tamburrino D, Baldoni A, et al. Molecular pathology of intraductal papillary mucinous neoplasms of the pancreas. World J Gastroenterol. 2014;20(29):10008-23.

29. Kitago M, Kitago M, Ueda M, Aiura K, Suzuki K, Hoshimoto S, et al. Comparison of K-ras point mutation distributions in intraductal papillary-mucinous tumors and ductal adenocarcinoma of the pancreas. Int J Cancer. 2004;110(2):177-82.

30. Wu J, Matthaei H, Maitra A, Dal Molin M, Wood LD, Eshleman JR, et al. Recurrent GNAS mutations define an unexpected pathway for pancreatic cyst development. Sci Transl Med. 2011;3(92): 92ra66.

31. Yamaguchi K, Chijiiwa K, Torata N, Kinoshita M, Tanaka M. Telomerase activity, P53 mutation and Ki-ras codon 12 point mutation of the peripheral blood in patients with hepato pancreato biliary diseases. HPB (Oxford). 2002;4(2):75-82.

32. Kobayashi N, Inamori M, Fujita K, Fujisawa T, Fujisawa N, Takahashi $\mathrm{H}$, et al. Characterization of K-ras gene mutations in association with mucinous hypersecretion in intraductal papillary-mucinous neoplasms. J Hepatobiliary Pancreat Surg. 2008;15(2):169-77.

33. Schönleben F, Qiu W, Remotti HE, Hohenberger W, Su GH. PIK3CA, KRAS, and BRAF mutations in intraductal papillary mucinous neoplasm/carcinoma (IPMN/C) of the pancreas. Langenbecks Arch Surg. 2008:393(3):289-96.

34. Schönleben F, Qiu W, Bruckman KC, Ciau NT, Li X, Lauerman MH, et al. BRAF and KRAS gene mutations in intraductal papillary mucinous neoplasm/carcinoma (IPMN/IPMC) of the pancreas. Cancer Lett. 2007;249(2):242-8

35. Toufektchan E, Toledo F. The guardian of the genome revisited: P53 downregulates genes required for telomere maintenance, DNA repair, and centromere structure. Cancers (Basel). 2018;10 (5). 
36. Miyasaka Y, Nagai E, Yamaguchi H, Fujii K, Inoue T, Ohuchida K, et al. The role of the DNA damage checkpoint pathway in intraductal papillary mucinous neoplasms of the pancreas. Clin Cancer Res. 2007;13(15 Pt 1):4371-7.

37. Wada K. p16 and p53 gene alterations and accumulations in the malignant evolution of intraductal papillary-mucinous tumors of the pancreas. J Hepatobiliary Pancreat Surg. 2002;9(1):76-85.

38. Hanoun N, Lulka H, Sicard F, Selves J, Buscail L, et al. Genetic and epigenetic alterations in pancreatic carcinogenesis. Curr Genomics. 2011;12(1):15-24.

39. Biankin A, Biankin SA, Kench JG, Morey AL, Lee C-S, Head V, et al. Aberrant p16(INK4A) and DPC4/Smad4 expression in intraductal papillary mucinous tumours of the pancreas is associated with invasive ductal adenocarcinoma. Gut. 2002:50(6):861-8.

40. Al-Turkmani MR, Gordon SR, Smith KD, Tsongalis GJ, Liu X. Pancreatic cyst fluid harboring a KRAS mutation. Cold Spring Harb Mol Case Stud. 2019;5(2).

41. Parkin CA, Ingham P W. The adventures of Sonic Hedgehog in development and repair. I. Hedgehog signaling in gastrointestinal development and disease. Am J Physiol Gastrointest Liver Physiol. 2008;294(2):G363-7

42. Jang K-T, Taek Lee K, Lee JG, Ho Choi S, Seok Heo J, Wook Cho $\mathrm{D}$, et al. Immunohistochemical expression of Sonic hedgehog in intraductal papillary mucinous tumor of the pancreas. Appl. Immunohistochem. Mol. Morphol. Appl Immunohistochem Mol Morphol. 2007;15(3):294-8.

43. Ohuchida K, Mizumoto K, Fujita H, Yamaguchi H, Konomi H, Nagai $\mathrm{E}$, et al. Sonic hedgehog is an early developmental marker of intraductal papillary mucinous neoplasms: clinical implications of mRNA levels in pancreatic juice. J. Pathol. 2006;210:42-8.

44. Hashimoto Y, Murakami Y, Uemura K, Hayashidani Y, Sudo T, Onge $\mathrm{H}$, et al. Telomere shortening and telomerase expression during multistage carcinogenesis of intraductal papillary mucinous neoplasms of the pancreas. J Gastrointest Surg. 2008;12(1):17-28; discussion 28-9.

45. Hong S-M, Park JY, Hruban RH, Goggins M. Molecular signatures of pancreatic cancer. Arch Pathol Lab Med. 2011;135(6):716-27.

46. Dal Molin M, Hong S-M, Hebbar S, Sharma R, Scrimieri F, de Wilde RF, et al. Loss of expression of the SWI/SNF chromatin remodeling subunit BRG1/SMARCA4 is frequently observed in intraductal papillary mucinous neoplasms of the pancreas. Hum Pathol. 2012; 43(4):585-91.

47. Smith ZD, Meissner A. DNA methylation: Roles in mammalian development. Nat Rev Genet. 2013;14(3):204-20.

48. Gopalakrishnan S, Van Emburgh BO, Robertson KD. DNA methylation in development and human disease. Mutat. Res. 2008;647(1-2): 30-8.

49. Sato N, Goggins M. Epigenetic alterations in intraductal papillary mucinous neoplasms of the pancreas. J. Hepatobiliary. Pancreat. Surg. 2006;13(4):280-285.

50. House MG, Guo M, lacobuzio-Donahue C, Herman JG. Molecular progression of promoter methylation in intraductal papillary mucinous neoplasms (IPMN) of the pancreas. Carcinogenesis. 2003; 24(2):193-8.

51. Hong S-M, Omura N, Vincent A, Li A, Knight S, Yu J, et al. Genomewide $\mathrm{CpG}$ island profiling of intraductal papillary mucinous neoplasms of the pancreas. Clin Cancer Res. 2012;18(3):700-12.

52. Sato N, Parker AR, Fukushima N, Miyagi Y, lacobuzio-Donahue CA, Eshleman JR, et al. Epigenetic inactivation of TFPI-2 as a common mechanism associated with growth and invasion of pancreatic ductal adenocarcinoma. Oncogene. 2005;24(5):850-8.

53. O'Brien J, Hayder H, Zayed Y, Peng C. Overview of microRNA biogenesis, mechanisms of actions, and circulation. Front Endocrinol (Lausanne). 2018;9:402. eCollection 2018

54. Słotwiński R, Lech G, Słotwińska SM. MicroRNAs in pancreatic cancer diagnosis and therapy. Cent Eur J Immunol. 2018;43(3): 314-324.

55. Wang L, Zheng J, Sun C, Wang L, Jin G, Xin L, et al. MicroRNA expression levels as diagnostic biomarkers for intraductal papillary mucinous neoplasm. Oncotarget. 2017;8(35):58765-58770.

56. Permuth-Wey J, Chen D-T, Fulp WJ, Yoder SJ, Zhang Y, Georgeades $\mathrm{C}$, et al. Plasma microRNAs as novel biomarkers for patients with intraductal papillary mucinous neoplasms of the pancreas. Cancer Prev Res (Phila). 2015;8(9):826-34.

57. Hernandez YG, Lucas AL. MicroRNA in pancreatic ductal adenocarcinoma and its precursor lesions. World J Gastrointest Oncol. 2016;8(1):18-29.

58. Caponi S, Funel N, Frampton AE, Mosca F, Santarpia L, Van der Velde $A G$, et al. The good, the bad and the ugly: a tale of miR-101, miR-21 and miR-155 in pancreatic intraductal papillary mucinous neoplasms. Ann Oncol. 2013;24(3):734-41.

59. Habbe N, Koorstra J-BM, Mendell JT, Johan Offerhaus G, Ryu JK, Feldmann G, et al. MicroRNA miR-155 is a biomarker of early pancreatic neoplasia. Cancer Biol Ther. 2009;8(4):340-6.

60. Negoi I, Hostiuc S, Sartelli M, Negoi RI, Beuran, M. MicroRNA-21 as a prognostic biomarker in patients with pancreatic cancer - A systematic review and meta-analysis. Am J Surg. 2017;214(3): 515-524.

61. Qu K, Zhang X, Lin T, Liu T, Wang Z, Liu S, et al. Circulating miRNA21-5p as a diagnostic biomarker for pancreatic cancer: Evidence from comprehensive miRNA expression profiling analysis and clinical validation. Sci Rep. 2017;7(1):1692.

62. G-y Hu, Tao F, Wang W, Ji K- w. Prognostic value of microRNA-21 in pancreatic ductal adenocarcinoma: A meta-analysis. World J Surg Oncol. 2016;14:82.

63. Giovannetti E, Funel N, Peters GJ, Del Chiaro M, Erozenci LA, Vasile $\mathrm{E}$, et al. MicroRNA-21 in pancreatic cancer: Correlation with clinical outcome and pharmacologic aspects underlying its role in the modulation of gemcitabine activity. Cancer Res. 2010; 70(11):4528-38.

64. Ji Y-F, Huang H, Jiang F, Ni R-Z, Xiao M-B. S100 family signaling network and related proteins in pancreatic cancer (Review). Int J Mol Med. 2014;33(4):769-76.

65. Bresnick AR, Weber DJ, Zimmer DB. S100 proteins in cancer. Nat Rev Cancer. 2015;15(2):96-109.

66. Donato R, Cannon BR, Sorci G, Riuzzi F, Hsu K, Weber DJ, et al. Functions of S100 proteins. Curr Mol Med. 2013;13 (1):24-57.

67. Leclerc $\mathrm{E}$, Vetter SW. The role of S100 proteins and their receptor RAGE in pancreatic cancer. Biochim Biophys Acta. 2015;1852(12): 2706-11.

68. Ohuchida K, Mizumoto K, Egami T, Yamaguchi H, Fujii K, Konomi H, et al. S100P is an early developmental marker of pancreatic carcinogenesis. Clin Cancer Res. 2006;12(18):5411-6.

69. Prica F, Radon T, Cheng Y, Crnogorac-Jurcevic T. The life and works of S100P - from conception to cancer. Am J Cancer Res. 2016; 6(2):562-76.

70. Chiang KC, Hsu JT, Chen HY, Jwo SC, Hwang TL, Jan YY, et al. Multifocal intraductal papillary mucinous neoplasm of the pancreas - a case report. World J Gastroenterol. 2009;15(5):628-32.

71. Beintaris I, Polymeros D, Krivan S, Triantafyllou K. Fish-mouth appearance of the ampulla of Vater. Ann Gastroenterol. 2013; 26(1):73.

72. Adsay V, Mino-Kenudson M, Furukawa T, Basturk 0, Zamboni G, Marchegiani G, et al. Pathologic Evaluation and Reporting of Intraductal Papillary Mucinous Neoplasms of the Pancreas and Other Tumoral Intraepithelial Neoplasms of Pancreatobiliary Tract: Recommendations of Verona Consensus Meeting. Ann Surg. 2016; 263(1):162-77.

73. Basturk O, Hong SM, Wood LD, Volkan Adsay N, Albores-Saavedra $\mathrm{J}$, Biankin AV, et al. A Revised Classification System and Recommendations From the Baltimore Consensus Meeting for Neoplastic Precursor Lesions in the Pancreas. Am J Surg Pathol. 2015;39(12):1730-41.

74. Sahora K, Mino-Kenudson M, Brugge W, Thayer SP, Ferrone CR, Sahani D, et al. Branch duct intraductal papillary mucinous neoplasms: does cyst size change the tip of the scale? A critical analysis of the revised international consensus guidelines in a large single-institutional series. Ann Surg. 2013;258(3):466-75.

75. Pergolini I, Sahora K, Ferrone CR, Morales-Oyarvide V, Wolpin BM, Mucci LA, et al. Long-term Risk of Pancreatic Malignancy in Patients With Branch Duct Intraductal Papillary Mucinous Neoplasm in a Referral Center. Gastroenterology. 2017;153(5):1284-1294.

76. Anand N, Sampath K, Wu BU. Cyst features and risk of malignancy in intraductal papillary mucinous neoplasms of the pancreas: a 
meta-analysis. Clin Gastroenterol Hepatol. 2013;11(8):913-21; quiz e59-60.

77. Castellano-Megías VM, Andrés CI, López-Alonso G, ColinaRuizdelgado F. Pathological features and diagnosis of intraductal papillary mucinous neoplasm of the pancreas. World J Gastrointest Oncol. 2014;6(9):311-24.

78. Grützmann R, Niedergethmann M, Pilarsky C, Klöppel G, Saeger HD. Intraductal papillary mucinous tumors of the pancreas: biology, diagnosis, and treatment. Oncologist. 2010;15 (12):1294-309.

79. Nagai K, Doi R, Kida A, Kami K, Kawaguchi Y, Ito T, et al. Intraductal papillary mucinous neoplasms of the pancreas: clinicopathologic characteristics and long-term follow-up after resection. World $J$ Surg. 2008;32(2);271-8; discussion 279-80.

80. Crippa S, Fernández-Del Castillo C, Salvia R, Finkelstein D, Bassi C Domínguez I, et al. Mucin-producing neoplasms of the pancreas: an analysis of distinguishing clinical and epidemiologic characteristics. Clin. Gastroenterol. Clin Gastroenterol Hepatol. 2010;8(2):213-9.

81. Terris B, Ponsot P, Paye F, Hammel P, Sauvanet A, Molas G, et al. Intraductal papillary mucinous tumors of the pancreas confined to secondary ducts show less aggressive pathologic features as compared with those involving the main pancreatic duct. Am J Surg Pathol. 2000;24(10):1372-7.

82. Salvia R, Crippa S, Partelli S, Armatura G, Malleo G, Paini M, et al. Differences between main-duct and branch-duct intraductal papillary mucinous neoplasms of the pancreas. World J Gastrointest Surg. 2010;2(10):342-6.

83. Turner BG, Brugge WR. Diagnostic and therapeutic endoscopic approaches to intraductal papillary mucinous neoplasm. World $\mathrm{J}$ Gastrointest Surg. 2010;2(10):337-41.

84. Rao V, Sarkar R, Smithies A, Razack A, Wedgwood K. Spontaneous gastro-pancreatic fistula - a hitherto unknown natural history of IPMN? J Surg Case Rep. 2012;(6);9.

85. Patel A, Allen A, Kuwahara J, Wadsworth T, Loeffler DM, Xie KL. Intraductal papillary mucinous neoplasm complicated by a gastropancreatic fistula. Radiol Case Rep. 2018;14(3):320-323.

86. Ren X, Zhu CL, Qin XF, Jiang H, Xia T, Qu YP. Co-occurrence of IPMN and malignant IPNB complicated by a pancreatobiliary fistula: A case report and review of the literature. World J Clin Cases. 2019;7(1): 102-108.

87. Komo T, Oishi K, Kohashi T, Hihara J, Kanou M, Nakashima A, et al. Pancreatobiliary fistula associated with intraductal papillary mucinous carcinoma accompanying obstructive jaundice: A case report. Int J Surg Case Rep. 2018;48:126-130.

88. Imaoka H, Yamao K, Salem AAS, Mizuno N, Takahashi K, Sawaki A, et al. Pseudomyxoma peritonei caused by acute pancreatitis in intraductal papillary mucinous carcinoma of the pancreas. Pancreas. 2006;32(2):223-4

89. Mizuta Y, Akazawa Y, Shiozawa K, Ohara H, Ohba K, Ohnita K, et al. Pseudomyxoma peritonei accompanied by intraductal papillary mucinous neoplasm of the pancreas. Pancreatology. 2005;5(4-5): 470-4.

90. Zapiach M, Yadav D, Smyrk TC, Fletcher JG, Pearson RK, Clain JE, et al. Calcifying obstructive pancreatitis: a study of intraductal papillary mucinous neoplasm associated with pancreatic calcification. Clin Gastroenterol Hepatol. 2004;2(1):57-63.

91. Kalaitzakis E, Braden B, Trivedi P, Sharifi Y, Chapman R. Intraductal papillary mucinous neoplasm in chronic calcifying pancreatitis: egg or hen? World J Gastroenterol. 2009:15(10):1273-5.

92. Gigot JF, Deprez P, Sempoux C, Descamps C, Metairie S, Glineur D, et al. Surgical management of intraductal papillary mucinous tumors of the pancreas: the role of routine frozen section of the surgical margin, intraoperative endoscopic staged biopsies of the Wirsung duct, and pancreaticogastric anastomosis. Arch Surg. 2001; 136(11):1256-62.

93. Pittman ME, Rao R, Hruban RH. Classification, morphology, molecular pathogenesis, and outcome of premalignant lesions of the pancreas. Arch Pathol Lab Med. 2017;141(12):1606-1614.

94. Nagata K, Horinouchi M, Saitou M, Higashi M, Nomoto M, Goto M, et al. Mucin expression profile in pancreatic cancer and the precursor lesions. J Hepatobiliary Pancreat Surg. 2007:14(3):243-54.

95. Yonezawa S, Higashi M, Yamada N, Goto M. Precursor Lesions of
Pancreatic Cancer. Gut Liver. 2008;2:137-154.

96. Adsay NV, Merati K, Andea A, Sarkar F, Hruban RH, Wilentz RE, et al. The dichotomy in the preinvasive neoplasia to invasive carcinoma sequence in the pancreas: differential expression of MUC1 and MUC2 supports the existence of two separate pathways of carcinogenesis. Mod Pathol. 2002;15(10):1087-95.

97. Masuda A, Arisaka Y, Hara S, Matsumoto I, Takenaka M, Sakai A, et al. MUC2 expression and prevalence of high-grade dysplasia and invasive carcinoma in mixed-type intraductal papillary mucinous neoplasm of the pancreas. Pancreatology. 2013;13(6):583-8.

98. Singhi AD, Koay EJ, Chari ST, Maitra A. Early Detection of Pancreatic Cancer: Opportunities and Challenges. Gastroenterology. 2019; 156(7):2024-2040.

99. Kanno A, Satoh K, Kimura K, Hirota M, Umino J, Masamune A, et al. The expression of MUC4 and MUC5AC is related to the biologic malignancy of intraductal papillary mucinous neoplasms of the pancreas. Pancreas. 2006;33(4):391-6.

100. Saitou M, Goto M, Horinouchi M, Tamada S, Nagata K, Hamada T, et al. MUC4 expression is a novel prognostic factor in patients with invasive ductal carcinoma of the pancreas. J Clin Pathol. 2005; 58(8):845-52.

101. Kanda M, Matthaei H, Wu J, Hong SM, Yu J, Borges M, et al. Presence of somatic mutations in most early-stage pancreatic intraepithelial neoplasia. Gastroenterology. 2012;142(4):730-733.

102. Matthaei H, Wu J, Dal Molin M, Shi C, Perner S, Kristiansen G, et al. GNAS sequencing identifies IPMN-specific mutations in a subgroup of diminutive pancreatic cysts referred to as 'incipient IPMNs'. Am J Surg Pathol. 2014;38(3):360-3.

103. Sauvanet A, Couvelard A, Belghiti J. Role of frozen section assessment for intraductal papillary and mucinous tumor of the pancreas. World J Gastrointest Surg. 2010;2(10):352-8.

104. Sereni E, Luchini C, Salvia R, Pea A. Molecular and clinical patterns of local progression in the pancreatic remnant following resection of pancreatic intraductal papillary mucinous neoplasm (IPMN). Chin Clin Oncol. 2019;8(2):21.

105. Fujii T, Kato K, Kodera $Y$, Kanda M, Nagai S, Yamada S, et al. Prognostic impact of pancreatic margin status in the intraductal papillary mucinous neoplasms of the pancreas. Surgery. 2010; 148(2):285-90.

106. Miller JR, Meyer JE, Waters JA, Al-Haddad M, Dewitt J, Sherman S, Lillemoe KD, Max Schmidt C. et al. Outcome of the pancreatic remnant following segmental pancreatectomy for non-invasive intraductal papillary mucinous neoplasm. HPB (Oxford). 2011: 13(11):759-66.

107. Frankel TL, LaFemina J, Bamboat ZM, D'Angelica MI, DeMatteo RP, Fong $Y$, et al. Dysplasia at the surgical margin is associated with recurrence after resection of non-invasive intraductal papillary mucinous neoplasms. HPB (Oxford). 2013;15(10):814-21.

108. Leng KM, Wang ZD, Zhao JB, Cui YF, Zhong XY. Impact of pancreatic margin status and lymph node metastases on recurrence after resection for invasive and noninvasive intraductal papillary mucinous neoplasms of the pancreas: a meta-analysis. Dig Surg. 2012;29(3):213-25.

109. Kang MJ, Jang JY, Bun Lee K, Rim Chang Y, Kwon W, Kim SW. Long-term prospective cohort study of patients undergoing pancreatectomy for intraductal papillary mucinous neoplasm of the pancreas: implications for postoperative surveillance. Ann Surg. 2014;260(2):356-63

110. Tamura K, Ohtsuka T, Ideno N, Aso T, Shindo K, Aishima S, et al. Treatment strategy for main duct intraductal papillary mucinous neoplasms of the pancreas based on the assessment of recurrence in the remnant pancreas after resection: a retrospective review. Ann Surg. 2014;259(2):360-8.

111. Matthaei H, Norris AL, Tsiatis AC, Olino K, Hong SM, dal Molin M, et al. Clinicopathological characteristics and molecular analyses of multifocal intraductal papillary mucinous neoplasms of the pancreas. Ann Surg. 2012;255(2):326-33.

112. Omori $Y$, Ono $Y$, Tanino $M$, Karasaki $H$, Yamaguchi $H$, Furukawa T, et al. Pathways of progression from intraductal papillary mucinous neoplasm to pancreatic ductal adenocarcinoma based on molecular features. Gastroenterology. 2019;156(3):647-661. 